\title{
Atypical Infections in Chronic Lymphocytic Leukemia and Mantle Cell Lymphoma Patients Treated with Ibrutinib
}

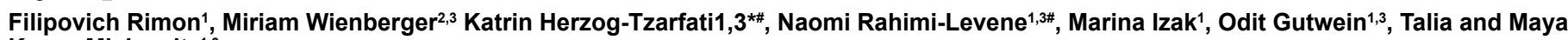
Koren-Michowitz ${ }^{1,3}$

${ }^{1}$ Institute of Hematology, Assaf Harofeh Medical Center, Zeriffin, Israel

${ }^{2}$ Infectious Disease Unit, Assaf Harofeh Medical Center, Zeriffin, Israel

${ }^{3}$ Sackler Faculty of Medicine, Tel Aviv University, Tel Aviv, Israel

\begin{abstract}
Ibrutinib is an oral Bruton's tyrosine kinase inhibitor with clinical efficacy in several B cell malignancies. In a pooled analysis of clinical trials evaluating ibrutinib, grade 3-4 infections were reported in $14 \%$ of patients. We screened consecutive patients on ibrutinib therapy for chronic lymphocytic leukemia (CLL) or mantle cell lymphoma (MCL) for infectious complications. Patients were hospitalized with documented infections uncommon to this patient population including Legionella pneumonia, Campylobacter bacteremia and fatal progressive multifocal leukoencephalopathy (PML). All patients received prior therapies for CLL/MCL. Immunological evaluation of these patients demonstrated immunoglobulin depression and profound lymphopenia with severe depletion in both B and CD4 T cell counts, suggesting defects in both humoral and T cell mediated immunity. This data support a broader immunosuppressive effect for ibrutinib than initially anticipated. While responding patients may show later recovery of B cell function, profound immunosuppression may occur at earlier treatment time points, particularly in previously treated patients. Closer patient monitoring during the first months of ibrutinib therapy may be desirable.
\end{abstract}

Keywords: Ibrutinib; Infection; Innate immunity; Progressive multifocal leukoencephalopathy

\section{Introduction}

Ibrutinib is an oral inhibitor of the Bruton's tyrosine kinase (BTK) enzyme [1], which is predominantly expressed in B lymphocytes, and is a major downstream mediator of signaling through the $B$ cell receptor (BCR). Ibrutinib has shown clinical efficacy in several B cell malignancies including chronic lymphocytic leukemia (CLL) [2-4], mantle cell lymphoma (MCL) [5] and Waldenström macroglobulinemia (WM) [6], both as a single agent and in combination with chemotherapy and immune therapies. Recently approved for these indications by both the FDA and EAMA, being the first drug that targets the BCR and the relative ease of oral delivery, it is expected to move into earlier treatment lines within the next few years.

Patients with lymphoproliferative neoplasms suffer from dysregulation of the immune system, predisposing them to a wide range of infections. Treatment of lymphoproliferative neoplasms is often associated with infectious complications, mainly during periods of severe neutropenia. Inherent humoral immunosuppression in CLL, depletion of normal B cells with monoclonal antibodies and the cellular immunosuppression related to treatment with nucleoside analogues further increase the risk of infections in patients with indolent $B$ cell malignancies, in particular after several lines of treatment. Recurrent infections with encapsulated bacteria are common in both untreated as well as treated CLL, Staphylococcus aureus and various gram-negative enteric pathogens predominate during periods of neutropenia, while Herpes simplex and Varicella- zoster infections are associated with prior nucleoside analogue treatment. Fungal infections are encountered less often [7]. In a pooled analysis of clinical trials evaluating ibrutinib, grade 3-4 infections were reported in $14 \%$ of patients resulting in death in $2 \%$ [8]. The frequency of grade $\geq 3$ infections in ibrutinib treated CLL patients $(n=132$, median follow-up $=3$ years) was recently reported to be greater in relapsed refractory patients (51\%) compared to treatment naive patients (13\%) [9]. The spectrum of infections included upper and lower respiratory tract infection, urinary tract infections, cellulitis, bacteremia, gastroenteritis, Clostridia and Staphylococcal infections. Treatment discontinuation due to infection was reported in $9 \%$ of patients in an analysis of 308 patients participating in four sequential ibrutinib trials [10]. Reported here is a series of CLL and MCL patients treated with ibrutinib who developed infections seen uncommonly in these diseases including Legionella pneumonia, Campylobacter bacteremia and progressive multifocal leukoencephalopathy (PML). Clinical and Immunological evaluation of these patients suggests that ibrutinib may target cells of the innate pathway in addition to suppressing B lymphocytes function, thus supporting it has a broader immunosuppressive effect that should be taken into account using this drug.

\section{Patients and Methods}

Consecutive patients receiving single agent ibrutinib therapy between April 2014 and July 2016 at the Institute of Hematology, Assaf Harofe Medical Center, were screened for documented infectious complications. Data were collected from patients' medical records. The study was approved by the institutional review board.

\section{Results}

Ibrutinib was approved by the Israeli health authorities and reimbursed for limited indications in January 2015 but has been available via companionate use since March 2014. In the screened time

*Corresponding author: Herzog-Tzarfati K, Department of Hematology, Assaf Harofeh Medical Center, Zeriffin, Israel 70300, Tel: 972-8-9779762; Fax: 972-89772; E-mail: katrinht@asaf.health.gov.il

Received July 13, 2017; Accepted July 17, 2017; Published July 31, 2017

Citation: Rimon F, Wienberger M, Herzog-Tzarfati K, Rahimi-Levene N, Izak M, et al. (2017) Atypical Infections in Chronic Lymphocytic Leukemia and Mantle Cell Lymphoma Patients Treated with Ibrutinib. J Blood Lymph 7: 172. doi: 10.4172/2165-7831.1000174

Copyright: ( 2017 Rimon F, et al. This is an open-access article distributed under the terms of the Creative Commons Attribution License, which permits unrestricted use, distribution, and reproduction in any medium, provided the original author and source are credited. 
Citation: Rimon F, Wienberger M, Herzog-Tzarfati K, Rahimi-Levene N, Izak M, et al. (2017) Atypical Infections in Chronic Lymphocytic Leukemia and Mantle Cell Lymphoma Patients Treated with Ibrutinib. J Blood Lymph 7: 172. doi: 10.4172/2165-7831.1000174

Page 2 of 4

period, we identified four patients treated with ibrutinib for either CLL $(n=3)$ or MCL $(n=1)$ who were hospitalized with an identified infection. All were tested negative for HIV. Baseline characteristics of hospitalized patients are provided in Table 1. Ibrutinib was given as $2^{\text {nd }}$ and $3^{\text {rd }}$ line of therapy in 1 and 3 patients, respectively. Median treatment duration with ibrutinib prior to infection was 5 (range 1-25) months, and the median dose immediately prior to hospitalization was $420 \mathrm{mg} /$ day (range $420 \mathrm{mg}$ /day-560 mg/day). Two patients were on preventive Intravenous Immunoglobulin (IVIG) treatment due to recurrent infections (infected bronchiectasis and recurrent sinusitis each in one) with the last infusion given 26 and 17 days prior to infection, respectively. Immunoglobulin (Ig) levels and immunophenotype of peripheral blood mononuclear cells (PBMC) are provided in Table 2. Serum Ig levels were reduced in three out of four patients prior to initiation of ibrutinib therapy and further decreased during treatment. All four patients had total white blood cell counts and absolute neutrophil counts within the normal range while on ibrutinib treatment. Three patients demonstrated marked lymphopenia with severely depleted B cell (CD19+) counts. Total number of T (CD3+) cells were within normal range or only mildly low while NK (CD3$\mathrm{CD} 56+)$ cells were below normal range in all four patients. CD4/CD8 ratio was significantly low in all four patients, with absolute CD4 counts ranging between 48 and 418 cells/microliter and half of them being below 200 cells/microliter. Patient characteristics and immunological profile for two additional patients on ibrutinib therapy, who did not develop infection, are provided in Table 3 . Both received ibrutinib as second line therapy, for CLL/SLL and MCL each in one patient, respectively. These patients had less severe lymphopenia, with normal B cell (CD19+) and T cell (CD3+) count and only mildly depleted NK cells and CD4/CD8 ratios.

\section{Discussion}

We report on uncharacteristic, opportunistic infections in a cohort of previously treated patients with lymphoproliferative neoplasms receiving single agent ibrutinib. Infections appeared at a median of 5 months after starting ibrutinib, and were manageable in three out of four patients, allowing resumption of ibrutinib therapy after control of the infectious episode. Patients with infections had low immunoglobulin levels, as well as profound lymphopenia of both CD4 $\mathrm{T}$ and $\mathrm{B}$ lineages and decreased NK cell counts.

The atypical infections documented in our patients are characteristic of immunocompromised hosts, and suggest impaired cellular, rather than humoral immune depression. Two of our patients had documented Campylobacter bacteremia. Campylobacter infections are endemic in Israel, which has one of the highest incidence rates reported among industrialized countries [11]. Campylobacter infection in immunocompetent individuals is generally restricted to the intestine, with bloodstream infection occurring in less than $1 \%$ of cases.

\begin{tabular}{|c|c|c|c|c|c|c|}
\hline $\begin{array}{l}\text { Patient } \\
\text { number }\end{array}$ & Age (years)/Gender & $\begin{array}{l}\text { Hematological } \\
\text { diagnosis }\end{array}$ & Comorbidity & Prior treatments & Infection & Outcome \\
\hline \multirow[t]{3}{*}{1} & \multirow[t]{3}{*}{$80 /$ male } & \multirow[t]{3}{*}{ CLL } & IHD & \multirow{3}{*}{$\begin{array}{l}\text { Obinatuzumab- } \\
\text { chlorambucil }\end{array}$} & \multirow{3}{*}{$\begin{array}{l}\text { Campylobacter jejuni } \\
\text { bacteremia }\end{array}$} & Alive \\
\hline & & & HTN & & & ibrutinib treatment continued \\
\hline & & & Dyslipidemia & & & \\
\hline \multirow[t]{2}{*}{2} & \multirow[t]{2}{*}{$67 /$ male } & \multirow[t]{2}{*}{ CLL } & \multirow[t]{2}{*}{ ESRD (dialysis) } & \multirow[t]{2}{*}{ FCR, BR } & \multirow[t]{2}{*}{ Legionella pneumonia } & Alive \\
\hline & & & & & & $\begin{array}{l}\text { ibrutinib treatment continued, } \\
\text { dose reduction }\end{array}$ \\
\hline \multirow[t]{2}{*}{3} & \multirow[t]{2}{*}{ 53/female } & \multirow[t]{2}{*}{ MCL } & HTN & R-CHOP/R-DHAP & \multirow{2}{*}{$\begin{array}{l}\text { Campylobacter coli } \\
\text { bacteremia }\end{array}$} & Alive \\
\hline & & & Hypothyroidism & ASCT, VRD & & ibrutinib treatment continued \\
\hline 4 & 58/female & CLL & & FCR, BR & PML & Death \\
\hline
\end{tabular}

CLL: Chronic Lymphocytic Leukemia; MCL: Mantle Cell lymphoma; HTN: Hypertension; IHD: Ischemic Heart Disease; ESRD: End Stage Renal Disease; R-CHOP Rituximab Cyclophosphamide Vincristine Prednisone; FCR: Fludarabine Cyclophosphamide Rituximab; BR: Bendamustine Rituximab; R-DHAP: Rituximab Dexamethasone High dose ARA -C (Cytarabine) Platinol (Cisplatin); ASCT: Autologous Stem Cell Transplant; VRD: Velcade (Bortezomib) Rituximab Dexamethasone; PML: Progressive Multifocal Leukoencephalopathy.

Table 1: Characteristics of study patients.

\begin{tabular}{|c|c|c|c|c|c|c|c|c|}
\hline \multirow{2}{*}{\begin{tabular}{|l|} 
Patient number \\
Ibrutinib treatment \\
\end{tabular}} & \multicolumn{2}{|c|}{1} & \multicolumn{2}{|c|}{2} & \multicolumn{2}{|c|}{3} & \multicolumn{2}{|c|}{4} \\
\hline & Prior & During & Prior & During & Prior & During & Prior & During \\
\hline $\begin{array}{l}\text { Immunoglobulins } \mathrm{g} / \mathrm{L} \\
\operatorname{lgG}^{1}\end{array}$ & $6.61^{1}$ & $3.36^{2}$ & $23^{2}$ & $22.8^{2}$ & $6.03^{1}$ & $0.67^{2}$ & $3.37^{2}$ & $4.1^{2}$ \\
\hline $\lg M^{1}$ & $1.18^{1}$ & $<0.17^{2}$ & $0.7^{2}$ & $0.24^{2}$ & $0.22^{1}$ & $<0.17^{2}$ & $<0.17^{2}$ & $<0.17^{2}$ \\
\hline $\lg \mathbf{A}^{1}$ & $0.43^{1}$ & $0.3^{2}$ & $17.2^{2}$ & $7.21^{2}$ & $1.08^{1}$ & $<0.06^{2}$ & $0.49^{2}$ & $0.14^{2}$ \\
\hline 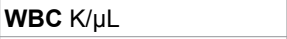 & 6.3 & 3.2 & 31.6 & 6.4 & 7.3 & 4 & 106 & 2.3 \\
\hline ANC K/ $\mu \mathrm{L}$ & 4.5 & 12.6 & 2.2 & 5.2 & 5.4 & 17.6 & 5.7 & 3.5 \\
\hline ALC K/ $/ \mu \mathrm{L}$ & 0.9 & 0.8 & 28 & 2.2 & 1 & 0.4 & 99 & 0.7 \\
\hline CD19 $\%{ }^{3} /$ number $\mathrm{K} / \mu \mathrm{L}$ & & 0 & & $29 / 0.64$ & & 0 & & $2 / 0.01$ \\
\hline CD3 $\% 3 /$ number $\mathrm{K} / \mu \mathrm{L}$ & & $78 / 0.6$ & & $57 / 1.25$ & & $90 / 0.36$ & & $89 / 0.62$ \\
\hline CD4 number cells/ $\mu \mathrm{L}$ & & 192 & & 418 & & 48 & & 250 \\
\hline $\begin{array}{l}\text { CD3-CD56+ } \%^{3} / \text { number } \\
\mathrm{K} / \mu \mathrm{L}\end{array}$ & & $4 / 0.03$ & & $2 / 0.044$ & & $3 / 0.01$ & & $5 / 0.035$ \\
\hline CD4/CD8 & & 0.48 & & 0.54 & & 0.15 & & 0.57 \\
\hline
\end{tabular}

${ }^{1}$ Normal IgG 7-16 g/L, IgM 0.4-2.3 g/L, IgA 0.7-5 g/L.

${ }^{2}$ Normal IgG 6.5-16 g/L, IgM 0.7-4 g/L, IgM 0.5-3 g/L.

${ }^{3}$ percent from total lymphocyte count.

WBC: White Blood Count; ANC: Absolute Neutrophil Count; ALC: Absolute Lymphocyte Count.

Table 2: Immunological results of study patients. 


\begin{tabular}{|c|c|c|c|c|c|}
\hline Patient number & \multicolumn{3}{|c|}{1} & \multicolumn{2}{|c|}{2} \\
\hline Age (years)/Gender & \multicolumn{3}{|c|}{$82 /$ female } & \multicolumn{2}{|c|}{$81 /$ male } \\
\hline $\begin{array}{l}\text { Hematological } \\
\text { diagnosis }\end{array}$ & \multicolumn{3}{|c|}{ CLL/SLL } & \multicolumn{2}{|c|}{$\mathrm{MCL}$} \\
\hline Comorbidity & \multicolumn{3}{|c|}{ None } & \multicolumn{2}{|c|}{ HTN } \\
\hline Prior treatments & \multicolumn{3}{|c|}{ Rituximab—chlorambucil } & \multicolumn{2}{|c|}{ R-CHOP/R-DHAP } \\
\hline Timing of analysis & $\begin{array}{l}\text { Prior to } \\
\text { ibrutinib }\end{array}$ & \multicolumn{2}{|c|}{ During ibrutinib } & $\begin{array}{l}\text { Prior to } \\
\text { ibrutinib }\end{array}$ & $\begin{array}{c}\text { During } \\
\text { ibrutinib }\end{array}$ \\
\hline $\begin{array}{l}\text { Immunoglobulins } \\
\text { g/L IgG1 }\end{array}$ & & $16.8^{2}$ & \multicolumn{2}{|c|}{$9.82^{2}$} & $10.2^{2}$ \\
\hline $\lg \mathbf{M}^{1}$ & & $0.29^{2}$ & \multicolumn{2}{|c|}{$0.53^{2}$} & $0.46^{2}$ \\
\hline $\lg \mathbf{A}^{1}$ & & $0.62^{2}$ & \multicolumn{2}{|c|}{$2.18^{2}$} & $2.02^{2}$ \\
\hline WBC $\mathrm{K} / \mu \mathrm{L}$ & & 13.2 & \multicolumn{2}{|c|}{4.5} & 4.1 \\
\hline 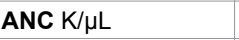 & & 7.7 & \multicolumn{2}{|c|}{3.1} & 2.2 \\
\hline 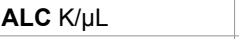 & & 4.7 & \multicolumn{2}{|c|}{0.8} & 1.3 \\
\hline $\begin{array}{l}\text { CD19 \% }{ }^{3} / \text { number } \\
\mathrm{K} / \mu \mathrm{L}\end{array}$ & & $66 / 3.1$ & \multicolumn{2}{|c|}{$10 / 0.08$} & $24 / 0.31$ \\
\hline $\begin{array}{l}\text { CD3 } \%{ }^{3} / \text { number } \\
\mathrm{K} / \mu \mathrm{L}\end{array}$ & & $27 / 1.27$ & \multicolumn{2}{|c|}{$82 / 0.66$} & $37 / 0.48$ \\
\hline $\begin{array}{l}\text { CD4 number cells/ } \\
\mu \mathrm{L}\end{array}$ & & 924 & \multicolumn{2}{|c|}{269} & 351 \\
\hline $\begin{array}{l}\text { CD3-CD56+ } \%^{2} \text { I } \\
\text { number } \mathrm{K} / \mu \mathrm{L}\end{array}$ & & $7 / 0.33$ & \multicolumn{2}{|c|}{ ND } & $3 / 0.04$ \\
\hline CD4/CD8 & & 0.67 & \multicolumn{2}{|c|}{0.93} & 1.35 \\
\hline
\end{tabular}

CLL: Chronic Lymphocytic Leukemia; SLL: Small Lymphocytic Lymphoma MCL: Mantle Cell lymphoma; HTN: Hypertension; R-CHOP: Rituximab Cyclophosphamide Vincristine Prednisone; R-DHAP: Rituximab Dexamethasone High dose ARA -C (Cytarabine) Platinol (Cisplatin); WBC: White Blood Count; ANC: Absolute Neutrophil Count; ALC: Absolute Lymphocyte Coun.

${ }^{1}$ Normal $\operatorname{lgG} 7-16 \mathrm{~g} / \mathrm{L}$, IgM 0.4-2.3 g/L, $\operatorname{lgA} 0.7-5 \mathrm{~g} / \mathrm{L}$.

${ }^{2}$ Normal IgG 6.5-16 g/L, IgM 0.7-4 g/L, IgM 0.5-3 g/L.

${ }^{3}$ percent from total lymphocyte count.

Table 3: Characteristics of patients without infection.

Susceptibility to bloodstream infection due to this pathogen has been documented in patients suffering from HIV infection, hematologic and solid malignancies, immunosuppressive therapy and other chronic diseases, or those undergoing organ transplantation [12]. Although hypoglobulinemia is a common manifestation in CLL, and is often observed after therapy with B cell depleting agents such as rituximab, Campylobacter sepsis has not been reported in this setting. This may suggest that suppression of $\mathrm{T}$ cell mediated immunity, possibly through modulation of the Toll -like receptor pathway [13] could be an important contributor to such infections in our patients. As far as we know these are the first reported cases of Campylobacter infection in the setting of ibrutinib therapy. Legionella pneumophila infection is also more frequent in the setting of cell mediated immune suppression. Immune control of this intracellular infection necessitates proper antigen presenting dendritic cell activity, as well as NK and T cell mediated IFN- $\gamma$ response [14]. As far as we know Legionella infection has not been previously reported in the setting of ibrutinib therapy.

PML, caused by the human polyomavirus JCV (John Cunningham virus), is a viral reactivation disease characteristically occurring in the setting of severe $\mathrm{T}$ cell depletion. With no effective therapy, it is almost unanimously fatal. Interestingly, the earliest reports of PML were in two CLL patients in the 1930's. With the emergence of the HIV epidemic, PML was most notably documented in this population. The implementation of effective antiviral therapy was followed by a substantial decrease in HIV associated PML, shifting the focus to immunosuppressive agents such as fludarabine and monoclonal antibodies. PML was not reported in ibrutinib-treated patients until recently [15]. A recent review of the FDA's adverse event reporting system detected ten cases of PML in patients treated with ibrutinib, five of them in combination with rituximab [16]. CD8+ T cells are the predominant immune cells found in proximity to PML lesions and are thought to be the primary suppressors of viral resurgence. It is currently presumed that lack of $\mathrm{CD} 4+$ and their role in immune surveillance and activation of CD8+ T cells are responsible for the high incidence of PML in HIV+ patients. Evidence suggests a role for $\mathrm{B}$ cells in JCV trafficking and viral life cycle. Monoclonal antibodies targeting both $\mathrm{T}$ and $\mathrm{B}$ cells have also been linked to development of PML [17]. With the introduction of targeted cancer therapies such as ibrutinib and idelalisib, their role in the development of PML is starting to evolve [16]. Ibrutinib is the first approved drug that targets the B cell receptor pathway. Our data, however, also supports strong inhibition of $\mathrm{T}$ and $\mathrm{NK}$ cell proliferation and/or activity, at least in previously treated patients. Absence of BTK activity, originally described in X linked agammaglobulinemia [18], is characterized by defects in B cell development and function as well as severe reduction in serum Ig levels. A recent retrospective analysis of Ig levels in treatment naïve $(n=52)$ and relapsed/refractory $(n=32)$ CLL patients treated with single agent ibrutinib was reported [19]. Compared with baseline values IgG levels decreased significantly 12 and 24 months after initiating ibrutinib, were unchanged at 6 months, IgM levels increased transiently at 6 and 12 months and IgA levels increased significantly at 6 months of treatment, and thereafter. Importantly, the rate of infections in this report was higher in the first 6 months of therapy, with lower infection rates on long term treatment correlating with the increase in IgA. This is in line with our data, demonstrating low Ig levels in patients with infections, at median 5 months ibrutinib therapy. In addition to its effect on B cells, data suggest that ibrutinib also modulate $\mathrm{T}$ cell, macrophage and NK cell function. IL2 inducible kinase (ITK), a member of the Tec kinase family, shares significant homology with BTK, and is inhibited by ibrutinib. Inhibition of ITK specifically depresses Th2 CD4 cells with preservation of Th1 and CD8 activity [20]. Inhibition of BTK activation in macrophages is associated with decreased phagocytic activity, which may enhance susceptibility to infection [21]. NK cells express both BTK and ITK, and their inhibition was associated with decreased innate immune responses to the TLR3 ligand, reduced expressions of IFN- $\gamma$, perforin, and granzyme-B and decreased cytotoxic activity [22]. Although we did not specifically test cellular immune cell functions, all four patients with infection demonstrated significantly depressed CD4 counts and low NK cell counts. Interestingly, Ahn et al. recently reported an increased rate of Pneumocystis jirovecii pneumonia in previously untreated CLL patients on single-agent ibrutinib [23]. Infections occurred at a median of 6 months on ibrutinib, and were not associated with decreased IgG or CD4 T cell levels. The differences in types of infection and $\mathrm{T}$ cell number in our report compared to the prior report could be partially explained by prior treatments given in our cohort. Hemodialysis in one of four patients, could also have contributed to the risk for infection in that case. In conclusion, we present a series of previously treated CLL/MCL patients, diagnosed with atypical infections early in the course of ibrutinib treatment. Some of these infections, Campylobacter bacteremia and Legionella pneumonia were reported here for the first time. PML has recently been linked to ibrutinib therapy and our report adds one more case to the growing evidence of this association. Immunological data for these patients supports impairment of cellular immunity characteristic of such infections. We believe that along with its very significant efficacy in $\mathrm{B}$ cell malignancies, ibrutinib may have a broader immunosuppressive effect than initially anticipated, particularly in the first months of therapy and in previously treated patients. As the drug becomes more widely available and moves into earlier lines of therapy, it is important 
Citation: Rimon F, Wienberger M, Herzog-Tzarfati K, Rahimi-Levene N, Izak M, et al. (2017) Atypical Infections in Chronic Lymphocytic Leukemia and Mantle Cell Lymphoma Patients Treated with Ibrutinib. J Blood Lymph 7: 172. doi: 10.4172/2165-7831.1000174

to explore the full spectrum of its effects on the immune system and develop strategies to decrease the risk of serious infections with this agent.

\section{References}

1. Honigberg LA, Smith AM, Sirisawad M, Vernera E, Loury D, et al. (2010) The Bruton tyrosine kinase inhibitor PCl-32765 blocks B-cell activation and is efficacious in models of autoimmune disease and B-cell malignancy. Proc Nat Acad Sci 107: 13075-13080.

2. Burger JA, Tedeschi A, Barr PM, Robak T, Owen C, et al. (2015) Ibrutinib as initial therapy for patients with chronic lymphocytic leukemia. $\mathrm{N}$ Engl J Med 373: 2425-2437.

3. Byrd JC, Brown JR, O'Brien S, Barrientos JC, Kay NE, et al. (2014) Ibrutinib versus Ofatumumab in Previously Treated Chronic Lymphoid Leukemia. N Engl J Med 371: 213-223.

4. Byrd JC, Furman RR, Coutre SE, Flinn IW, Burger JA, et al. (2013) Targeting BTK with ibrutinib in relapsed chronic lymphocytic leukemia. N Engl J Med 369: 32-42.

5. Wang ML, Rule S, Martin P, Peter Martin, Andre Goy, et al. (2013) Targeting BTK with ibrutinib in relapsed or refractory mantle-cell lymphoma. N Engl J Med 369: 507-516.

6. Treon SP, Tripsas CK, Meid K, Warren D, Varma G, et al. (2015) Ibrutinib in Previously Treated Waldenström's Macroglobulinemia. N Engl J Med 372: 1430-1440.

7. Nosari A (2012) Infectious complications in chronic lymphocytic leukemia. Mediterr. J Hematol Infect Dis 4: e2012070.

8. Pauff JM, Tillman BF, Talbott M, Satyanarayana G, Warner J (2016) Integrated infectious toxicity analysis of the BTK inhibitor ibrutinib. J Clin Oncol.

9. Byrd JC, Furman RR, Coutre SE, Burger JA, Blum KA, et al. (2015) Three-year follow-up of treatment-naive and previously treated patients with CLL and SLL receiving single-agent ibrutinib. Blood 125: 2497-2506.

10. Maddocks KJ, Ruppert AS, Lozanski G, Heerema NA, Zhao W, et al. (2015) Etiology of Ibrutinib Therapy Discontinuation and Outcomes in Patients With Chronic Lymphocytic Leukemia. JAMA Oncol 1:80-87.

11. Weinberger M, Lerner L, Valinsky L, Moran-Gilad J Nissan I, et al. (2013)
Increased incidence of Campylobacter spp. infection and high rates among children, Israel. Emerg Infect Dis 19:1828-1831.

12. Pacanowski J, Lalande V, Lacombe K, Boudraa C, Lesprit P, et al. (2008) Campylobacter bacteremia: clinical features and factors associated with fatal outcome. Clin Infect Dis 47: 790-796.

13. Janssen R, Krogfelt KA, Cawthraw SA, van Pelt W, Wagenaar JA, et al. (2008) Host-pathogen interactions in Campylobacter infections: The host perspective. Clin Microbiol Rev 21: 505-518.

14. Friedman H, Yamamoto $Y$, Klein TW (2002) Legionella pneumophila pathogenesis and immunity. Semin Pediatr Infect Dis 13: 273-279.

15. Lutz M, Schulze AB, Rebber E, Wiebe S, Zoubi T, et al. (2016) Progressive Multifocal Leukoencephalopathy after Ibrutinib Therapy for Chronic Lymphocytic Leukemia. Cancer Res Treat 49: 548-552.

16. Raisch DW, Rafi JA, Chen C, Bennett CL (2016) Detection of cases of progressive multifocal leukoencephalopathy associated with new biologicals and targeted cancer therapies from the FDA's adverse event reporting system. Expert Opin Drug Saf 15:1003-1011.

17. Beltrami S, Gordon J (2013) Immune surveillance and response to JC virus infection and PML. J Neurovirol 20: 137-149.

18. Tsukada S, Saffran DC, Rawlings DJ, Parolini O, Allen RC, et al. (1993) Deficient expression of a B cell cytoplasmic tyrosine kinase in human $\mathrm{X}$-linked agammaglobulinemia. Cell 72: 279-290.

19. Sun C, Tian X, Lee Shan Y, Gunti S, Lipsky A, et al. (2015) Partial reconstitution of humoral immunity and fewer infections in patients with chronic lymphocytic leukemia treated with ibrutinib. Blood 126: 2213-2219.

20. Dubovsky JA, Beckwith KA, Natarajan G, Woyach JA, Jaglowski S, et al. (2013) Ibrutinib is an irreversible molecular inhibitor of ITK driving a Th1-selective pressure in T lymphocytes. Blood 122: 2539-2549.

21. Fiorcari S, Maffei R, Audrito V, Martinelli S, Hacken ET, et al. (2016) Ibrutinib modifies the function of monocyte/macrophage population in chronic lymphocytic leukemia. Oncotarget 7: 65968-65981.

22. Bao Y, Zheng J, Han C, Jin J, Han H, et al. (2012) Tyrosine kinase Btk is required for NK cell activation. J Biol Chem 287: 23769-23778.

23. Ahn IE, Jerussi T, Farooqui M, Tian X, Wiestner A, et al. (2016) Atypical Pneumocystis jirovecii pneumonia in previously untreated patients with CLL on single-agent ibrutinib. Blood 128: 1940-1943. 